\title{
In vitro antitumor activity of the ethyl acetate extract of Potentilla chinensis in osteosarcoma cancer cells
}

\author{
GUANG WAN, JIN-GANG TAO, GUO-DONG WANG, SHEN-PENG LIU, \\ HONG-XING ZHAO and QIU-DONG LIANG
}

Department of Orthopedics, The First Affiliated Hospital of Xinxiang Medical University, Weihui, Henan 453100, P.R. China

Received June 18, 2015; Accepted July 4, 2016

DOI: $10.3892 / \mathrm{mmr} .2016 .5679$

\begin{abstract}
The aim of the current study was to evaluate the anticancer effect of the ethanol extract of Potentilla chinensis, a Chinese medicinal plant. An MTT assay was used to evaluate the cell viability of MG-63 human osteosarcoma cancer cells and fR- 2 cells. Furthermore, the effect of the extract on apoptosis induction, cell cycle phase distribution and inhibition of cell migration in the MG63 human osteosarcoma cancer cell line was evaluated. The effect of the extract on cell cycle phase distribution was assessed by flow cytometry using propidium iodide (PI). Phase contrast microscopy detected the morphological changes in MG63 cancer cells following extract treatment. The results of the study demonstrated that the extract was cytotoxic to MG63 cancer cells, while the normal cell line (epithelial cell line) showed lower susceptibility. Phase contrast microscopy showed distinguishing morphological features, such as cell shrinkage and blebbing induced by the extract treatment in osteosarcoma cancer cells. The average proportion of Annexin V-positive cells (total apoptotic cells) significantly increased from 5.6\% in the control to $24.2,38.8$ and $55.7 \%$ in the 40,80 and $150 \mu \mathrm{g} / \mathrm{ml}$ groups, respectively. The extract induced early and late apoptosis in the cancer cells. Flow cytometric analysis revealed that the extract induced G0/G1-cell cycle arrest, which also showed significant dose-dependence. The extract induced a significant and concentration-dependent reduction in cell migration. Moreover, DNA fragmentation was also examined by observation of the formation of DNA ladders. It was demonstrated that DNA fragmentation was increased with extract concentration compared with that in the control. Taken together, EEPC may serve as potential therapeutic agent against osteosarcoma,
\end{abstract}

Correspondence to: Dr Qiu-Dong Liang, Department of Orthopedics, The First Affiliated Hospital of Xinxiang Medical University, 88 Jiankang Road, Weihui, Henan 453100, P.R. China

E-mail: liangqd053@gmail.com

Key words: Potentilla chinensis, osteosarcoma, cell cycle arrest, cell migration provided that the toxicity profile and in vivo investigations demonstrate that it is safe.

\section{Introduction}

Osteosarcoma is the most widespread type of malignant bone tumor in children and teenagers, which accounts for $2.4 \%$ of all pediatric cancers and $\sim 20 \%$ of all primary bone malignancies. Osteosarcoma has been described to be more predominant in males compared with females, with the highest rates of occurrence during adolescence $(1,2)$. Chemotherapy and surgery are the main therapies used in the management of osteosarcoma; however, there are several difficulties associated with the high dosages of chemotherapeutic agents that patients receive. A number of patients with osteosarcoma do not show any response to chemotherapy due to the development of multidrug resistance in cancer cells. In addition, there are several serious side effects associated with chemotherapy, including decreased renal function and gonadal and cardiac dysfunction (3-5). Consequently, there is an urgent requirement for the identification of novel chemotherapeutic agents with enhanced activity and less likelihood of resistance for the treatment of osteosarcoma. The main aim of cancer drug research is to develop therapeutic agents that are effective, safe and affordable. An integrative approach for managing a patient with osteosarcoma should target the numerous biochemical and physiological pathways that support tumour development and minimize normal-tissue toxicity. In the past 50 years, a large number of plant-derived bioactive compounds have been isolated that are now used to treat different types of malignant cancer. A number of studies have focused on natural products extracted from Chinese medicinal herbs as anticancer agents in cancer therapy. Over $60 \%$ of the current anticancer drugs originate from natural sources. Nature continues to be the most productive source of biologically active and diverse chemotypes (6).

Potentilla Linnaeus (L.) is one of a hundred genera in the rose family (Rosaceae), subfamily Rosoideae, tribe Potentilleae (7). The genus name Potentilla derives from the Latin diminutive of potens meaning 'powerful' in reference to the medicinal properties of certain species. The genus Potentilla includes $~ 500$ species of perennial, biennial, and annual herbs and small shrubs with rhizomes. In Chinese traditional medicine Potentilla extracts have been used to treat 
diarrhea, hepatitis, rheuma and scabies, as well as a remedy for detoxification $(8,9)$. Different parts of Potentilla chinensis have been used in oriental medicine against diseases, such as dysentery and carbunculosis. Pharmacological studies on Potentilla chinensis revealed that it has hypoglycemic and anti-inflammatory activities $(10,11)$. Chinese authors have attributed significant anticancer activity to a number of triterpenoid compounds isolated from the aerial parts of Potentilla chinensis and the roots of Potentilla multicaulis, which were evaluated for their in vitro cytotoxic activities against SMMC-7221 human hepatoma and HL-60 human promyelocytic leukemia cells $(12,13)$. Various previously published phytochemical reports on Potentilla chinensis have revealed the presence of various triterpenes, such as 3-hydroxy-11-ursen-28, 13-olide, 11,12-dehydroursolic acid lactone, 3-O-acetyl pomolic acid, betulinic acid, 3-oxo-12-ursen-28-oic acid, ursolic acid and oleanic acid (14).

The present study aimed to determine the anticancer effects of the ethanol extract of the roots of Potentilla chinensis against MG63 osteosarcoma cancer cells by investigating its effects on apoptosis induction, cell cycle arrest, inhibition of cell migration and DNA damage, which to the best of our knowledge constitutes the first such report on this plant species.

\section{Materials and methods}

Plant material and extraction procedure. Potentilla chinensis was collected during July-August 2014 from a local region of Henan, China. The plant material was confirmed by a well-known taxonomist. The roots of Potentilla chinensis were thoroughly washed with tap water, shade dried and then chopped into small pieces. Ethanol (95\%) was used for hot extraction, which was conducted for $3 \mathrm{~h}$ using a soxhlet extraction apparatus. The extract was then concentrated under reduced pressure in a rotary evaporator at $45^{\circ} \mathrm{C}$ and was then kept in a refrigerator at $4^{\circ} \mathrm{C}$ prior to use

Chemicals and reagents. RPMI-1640 growth medium (Hangzhou Sijiqing Biological Products Co., Ltd., Hangzhou, China), minimum essential medium (MEM), fetal calf serum (Gibco, Thermo Fisher Scientific, Inc., Waltham, MA, USA), trypsin, penicillin, MTT, streptomycin, dimethyl sulfoxide (DMSO) and phosphate-buffered saline (PBS) were used in this study. The MTT kit was obtained from Roche Diagnostics (Indianapolis, IN, USA). Annexin V-Fluorescein Isothiocyanate (FITC)-Propidium Iodide (PI) Apoptosis Detection kit was purchased from Sigma-Aldrich (St. Louis, MO, USA). Hoechst dye was purchased from Sigma-Aldrich. All other chemicals and solvents used were of the highest purity grade. Cell culture plastic ware was purchased from BD Biosciences (San Jose, CA, USA).

Cell lines and culture conditions. The MG63 human osteosarcoma cell line and fR-2 normal epithelial cell line were obtained from Shanghai Institute of Cell Resource Center of Life Science (Shanghai, China). All cells were grown in a humidified $5 \% \mathrm{CO}_{2}$ atmosphere at $37^{\circ} \mathrm{C}$ in an incubator, and cultured in RPMI-1640 medium supplemented with $10 \%$ heat-inactivated newborn calf serum, $100 \mathrm{IU} / \mathrm{ml}$ penicillin and $100 \mu \mathrm{g} / \mathrm{ml}$ streptomycin.
Analysis of cell viability using an MTT assay. Inhibition of cell proliferation of the extract was measured using an MTT assay. Briefly, MG63 and fR-2 cells were plated in 96 -well culture plates $\left(1 \times 10^{5}\right.$ cells/well) separately. After $24 \mathrm{~h}$ incubation, cells were treated with the ethyl acetate extract of Potentilla chinensis (EEPC) $(0,5,10,20,40$, 80 and $150 \mu \mathrm{g} / \mathrm{ml}$, eight wells per concentration) for 24 or $48 \mathrm{~h}$. MTT solution $(10 \mathrm{mg} / \mathrm{ml})$ was then added to each well. After $4 \mathrm{~h}$ incubation, the formazan precipitate was dissolved in dimethyl sulfoxide $(100 \mu \mathrm{l})$ and then the absorbance was measured in an enzyme-linked immunosorbent assay reader (Thermo Molecular Devices Co., Union City, CA, USA) at $570 \mathrm{~nm}$. The cell viability ratio was calculated by the following formula: Inhibitory ratio $(\%)=(\mathrm{OD}$ control-OD treated $) /(\mathrm{OD}$ control $) \times 100$.

Cell morphological study by phase contrast microscopy. Phase contrast microscopy was conducted to assess the morphological alterations in the MG63 osteosarcoma cancer cells. The cells were incubated for $24 \mathrm{~h}$ and treated with EEPC extract at various concentrations $(0,40,80$ and $150 \mu \mathrm{g} / \mathrm{ml})$. Control cells treated with $0.5 \%$ DMSO alone were also included. The morphological changes, characteristic of apoptosis or necrosis, were observed and the images were captured under an inverted light microscope (Olympus America, Inc., Center Valley, PA, USA) after 24 and $48 \mathrm{~h}$.

Annexin $V$ binding assay/quantification of apoptotic cell death. To establish and confirm cells undergoing apoptosis, an Annexin $\mathrm{V}$ binding assay was performed through flow cytometry. Briefly, MG63 cancer cells were treated with the EEPC extract $(0,40,80$ and $150 \mu \mathrm{g} / \mathrm{ml})$ for $48 \mathrm{~h}$, and then treated and untreated cells were harvested by trypsinization. Harvested cells were then incubated in Annexin V-FITC (50 ng/ml) and PI $(50 \mu \mathrm{g} / \mathrm{ml})$, at room temperature for $20 \mathrm{~min}$ in the dark, and analyzed using a FACS Calibur flow cytometer (BD Biosciences) taking a minimum of 20,000 cells in each sample.

Cell cycle analysis. MG63 cells $\left(5 \times 10^{6}\right)$ were seeded in $60-\mathrm{mm}$ dishes and subjected to various concentrations ( 0 , 40, 80 and $150 \mu \mathrm{g} / \mathrm{ml}$ ) of the EEPC for $48 \mathrm{~h}$. Floating and adherent cells were collected by trypsinization and washed three times with PBS. Cells were incubated in $70 \%$ ethanol at $-20^{\circ} \mathrm{C}$ overnight, treated with $20 \mu \mathrm{g} / \mathrm{ml}$ RNase A and stained with $2.0 \mu \mathrm{g} / \mathrm{ml}$ PI. Finally the stained cells were analyzed by Flow cytometry at a wavelength of $488 \mathrm{~nm}$ using a FACS Calibur instrument (BD Biosciences) equipped with CellQuest software, version 3.3 (BD Biosciences).

DNA fragmentation analysis following EEPC treatment. The MG63 cells ( $1 \times 10^{5}$ cells/dish) were plated in a $6-\mathrm{cm}$ dish and then subjected to treatment with various concentrations $(0,40,80$ and $150 \mu \mathrm{g} / \mathrm{ml})$ of the EEPC for $48 \mathrm{~h}$. After drug treatment, the cells were washed with ice-cold PBS and resuspended in lysis buffer $(25 \mathrm{mM}$ Tris- $\mathrm{HCl}, \mathrm{pH} 7.4,5 \mathrm{mM}$ EDTA and $0.6 \% \mathrm{SDS}$ ) with $1.0 \mathrm{mg} / \mathrm{ml}$ RNase A for $15 \mathrm{~min}$ at $50^{\circ} \mathrm{C}$. Proteinase $\mathrm{K}$ was added and the cells were incubated overnight. Separation of DNA was conducted using $2 \%$ agarose gel and detected under UV light after staining with ethidium bromide. 
In vitro wound healing assay. This assay was performed using a standard method (10). Cells $\left(1 \times 10^{5}\right.$ cells $\left./ \mathrm{ml}\right)$ were seeded in a 6-well plate and incubated at $37^{\circ} \mathrm{C}$ until a monolayer of 95-100\% confluent cells was obtained. Subsequent to $12 \mathrm{~h}$ of starvation, a $500 \mathrm{ml}$ pipette tip was used to create a straight cell-free wound. Each well was washed twice with PBS to remove any debris and then exposed to various concentrations of EEPC extract $(0,40,80$ and $150 \mu \mathrm{g} / \mathrm{ml})$ in a medium. After $48 \mathrm{~h}$ of incubation, the cells were fixed and stained with 5\% ethanol containing $0.5 \%$ crystal violet powder for $20 \mathrm{~min}$, and randomly selected fields were photographed under a light microscope. The number of cells that migrated into the scratched area were counted.

Statistical analysis. All data were derived from at least three independent experiments. The results are expressed as the mean \pm standard deviation. Differences between groups were analyzed using Student's t-test. GraphPad Prism, version 5.0 (GraphPad Software, Inc., La Jolla, CA, USA) was used for statistical analyses. $\mathrm{P}<0.05$ was considered to indicate a statistically significant difference.

\section{Results}

EEPC exhibits potent and selective anticancer activity. The EEPC was evaluated for antiproliferative activity using the MTT assay against the MG63 human osteosarcoma cancer cells and an fR-2 normal cell line (epithelial cell line) for 24 and 48 h (Figs. 1 and 2). The extract exhibited potent. dose-dependent and selective cytotoxic activity against MG63 cancer cells. With the aim of investigating the toxic effects of the extract on normal cells, the cytotoxic effects of the extract against fR-2 normal epithelial cells was also assessed (Fig. 2). The results showed that the extract resulted in decreased cytotoxicity towards the normal cell line, and as such was specific towards the cancer cells. The effect of the EEPC extract on the MG63 osteosarcoma cancer cell growth was estimated by MTT assay conducted for two different time durations, 24 and $48 \mathrm{~h}$. The results showed that the cytotoxic effect of the extract showed dose and time-dependence.

Effect of EEPC extract on cellular morphology of MG-63 cancer cells using inverted light microscopy. Morphological analysis using inverted light microscopy revealed that EEPC extract induced growth inhibition and apoptosis in MG-63 osteosarcoma cancer cells. As shown in Fig. 3A-D, the number of cells in the control and the ones treated with different concentrations of EEPC extract increased. The cells with higher doses revealed that cellular shrinkage and blebbing occurred. This effect was shown to be associated with EEPC extract dose. The number of cells with altered morphology increased with EEPC extract concentration.

Quantification of apoptotic cell death by Annexin V binding assay. Translocation of phosphatidylserine to the exterior surface of the plasma membrane is a unique feature of early apoptosis, which can be recognized and detected by binding of Annexin V-FITC. If cell death occurs, fragmented and damaged DNA becomes permeable for binding with PI. After cells are stained with Annexin V in tandem

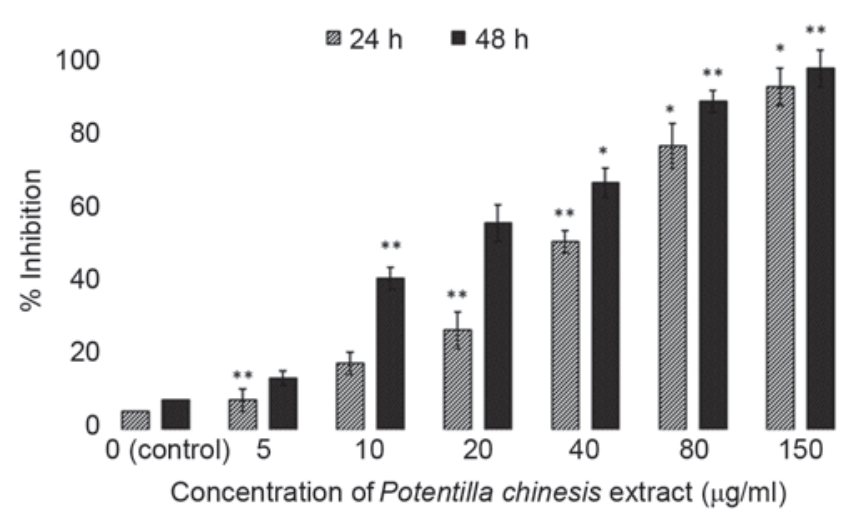

Figure 1. Cytotoxic effect of ethyl acetate extract of Potentilla chinensis in MG63 human osteosarcoma cancer cells at two different time intervals and different extract doses. Data are expressed as the mean \pm standard deviation of three independent experiments. ${ }^{*} \mathrm{P}<0.05$ and ${ }^{* *} \mathrm{P}<0.01$ vs. $0 \mu \mathrm{M}$ (control).

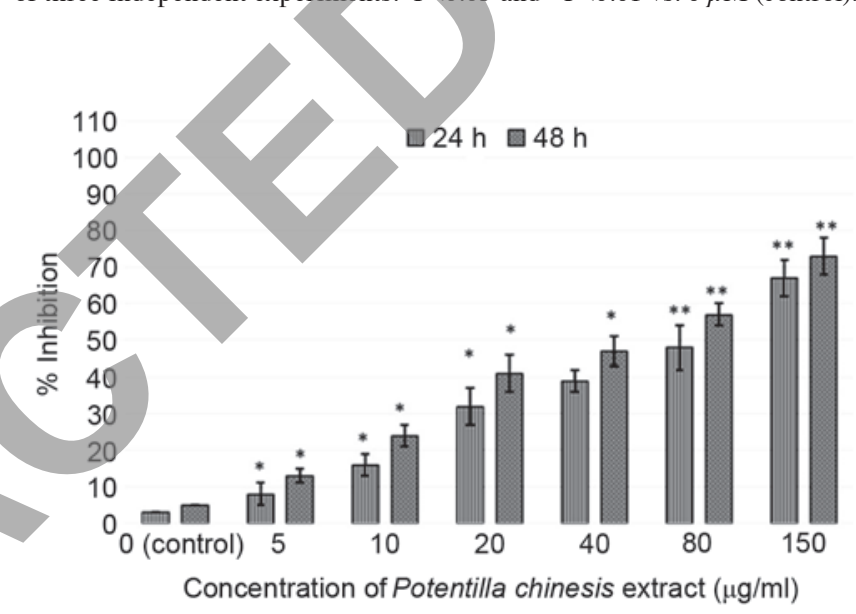

Figure 2. Cytotoxic effect of ethyl acetate extract of Potentilla chinensis in fR-2 human epithelial cell line at two different time intervals and different extract concentrations. Data are expressed as the mean \pm standard deviation of three independent experiments. ${ }^{*} \mathrm{P}<0.05$ and ${ }^{* *} \mathrm{P}<0.01$ vs. $0 \mu \mathrm{M}$ (control).

with PI, this reagent enters the cell only when the plasma cell membrane is damaged. In this study, flow cytometry revealed that in the extract-treated cells, a higher number of cells were positive for Annexin V compared with control (no drug treatment) (Fig. 4). The percentage of viable cells was low at lower concentration of the extract. However, at higher dosages, the total number of apoptotic cells considerably increased following treatment with 80 and $150 \mu \mathrm{g} / \mathrm{ml}$ doses of the extract. When the cells were treated with 40,80 and $150 \mu \mathrm{g} / \mathrm{ml}$ of the EEPC extract for $48 \mathrm{~h}$, the average proportion of Annexin V-staining positive cells (total apoptotic cells) markedly increased from $5.6 \%$ in control to $24.2,38.8$ and $55.7 \%$, respectively. Thus, this assay allows a quantitative estimation of the apoptotic cell death following drug exposure.

Effect of the EEPC extract on cell cycle phase distribution in MG-63 cancer cells. Apoptosis and the cell cycle are closely related biochemical processes, and any disruption in cell cycle progression may finally lead to apoptotic cell death. In order to have a mechanistic indication of the growth inhibitory effect exerted by the extract in MG-63 cancer cells, flow cytometry analysis was conducted to identify whether the 

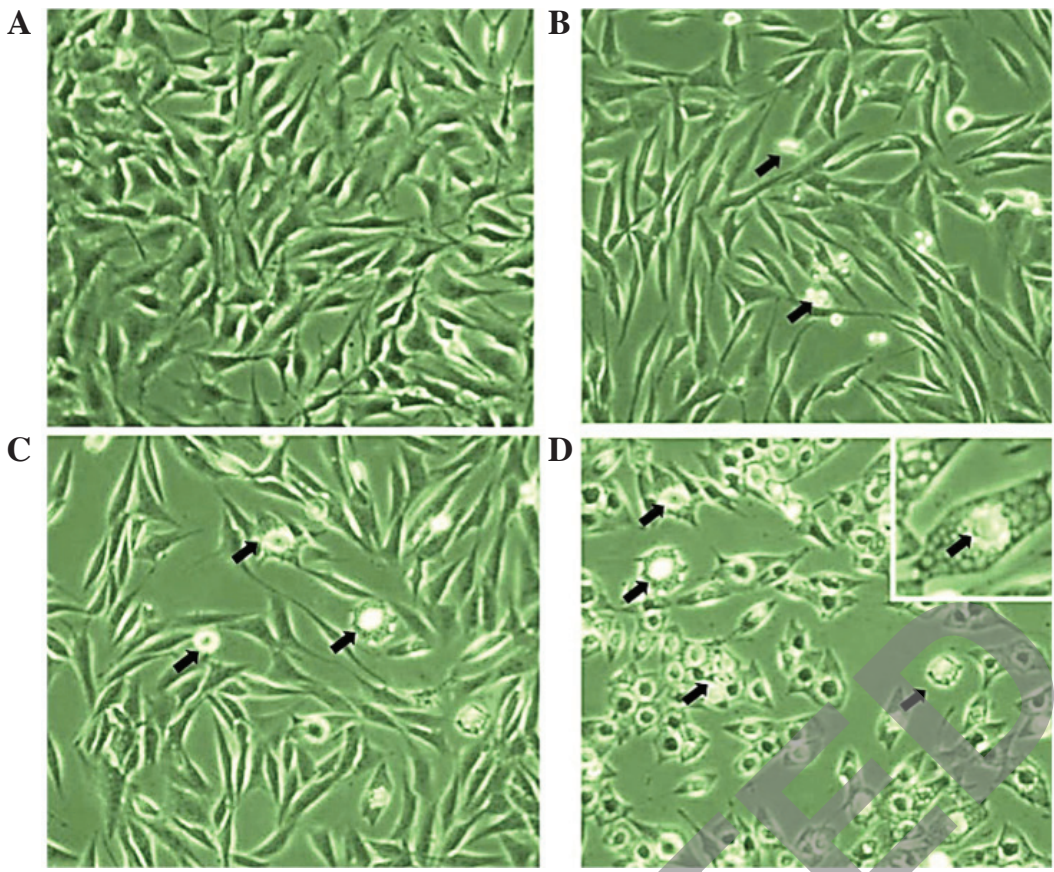

Figure 3. EEPC inhibited the growth of MG63 osteosarcoma cancer cells as shown by inverted light microscopy. Morphological changes of the cells after treatment with EEPC (magnification, x200). Cellular shrinkage was observed in EEPC-treated cells (arrows). MG63 cells were treated with (A) $0 \mu \mathrm{g} / \mathrm{ml}$ (control), (B) $40 \mu \mathrm{g} / \mathrm{ml}$, (C) $80 \mu \mathrm{g} / \mathrm{ml}$ and (D) $150 \mu \mathrm{g} / \mathrm{ml}$ EEPC extract. The number of cells with shrinkage increased with an increase in the dose of the extract. EEPC, ethyl acetate extract of Potentilla chinensis.

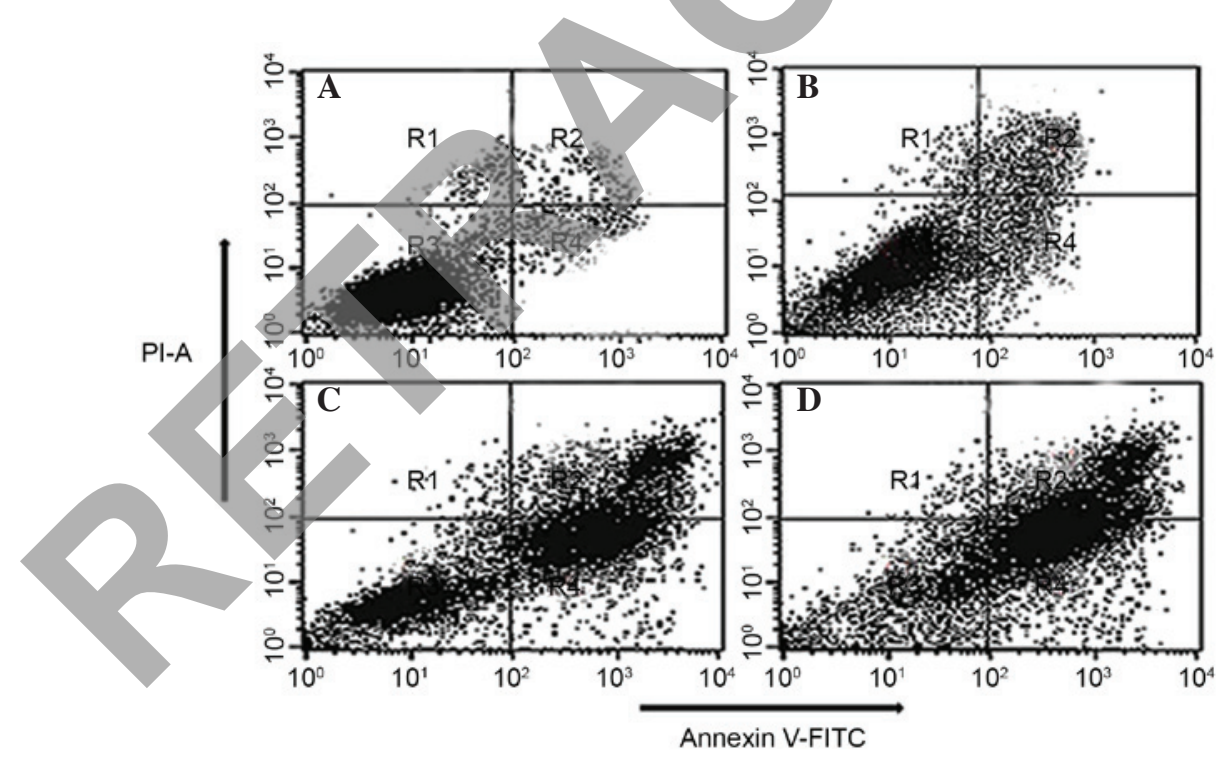

Figure 4. Quantification of apoptosis induced by EEPC extract in MG63 osteosarcoma cancer cells evaluated by Annexin V-FITC/PI dual staining. The cells were treated with (A) $0 \mu \mathrm{g} / \mathrm{ml}$ (control), (B) $40 \mu \mathrm{g} / \mathrm{ml}$, (C) $80 \mu \mathrm{g} / \mathrm{ml}$ and (D) $150 \mu \mathrm{g} / \mathrm{ml}$ of the EEPC extract for $48 \mathrm{~h}$ and analyzed using fluorescence-activated cell sorting. R1, R2, R3 and R4 quadrants show percentage of necrotic, early apoptotic, normal healthy and late apoptotic cell populations, respectively. EEPC, ethyl acetate extract of Potentilla chinensis, FITC, flusorescein isothiocyanate; PI, propidium iodide.

extract induces cell cycle arrest in this cell line. The results revealed that EEPC extract induces sub-G1 cell cycle arrest and increases the fraction of MG-63 apoptotic cells. To determine the distribution of EEPC extract-treated MG-63 cells in different phases of the cell cycle, DNA content in cells was detected by PI staining and flow cytometry. The extract induced sub-G1 cell cycle arrest with a substantial increase in the number of apoptotic cells. The results showed that treatment with different concentrations of the extract for $48 \mathrm{~h}$ led to an increase in the population of cells in the sub-G0/G1 phase (apoptotic population) $(\mathrm{P}<0.01)$ (Fig. 5A-D). This upsurge in the sub-G1 population was accompanied by a corresponding reduction of the cells in the s-phase and G2/M phases of the cell cycle. As compared with the control (Fig. 5A), extract treated (Fig. 5B-D) cells showed a significant proportion of apoptotic cells.

Effect of EEPC extract on DNA fragmentation in $M G-63$ human osteosarcoma cancer cells. Besides the morphological changes to extract-treated MG-63 cells, DNA fragmentation 


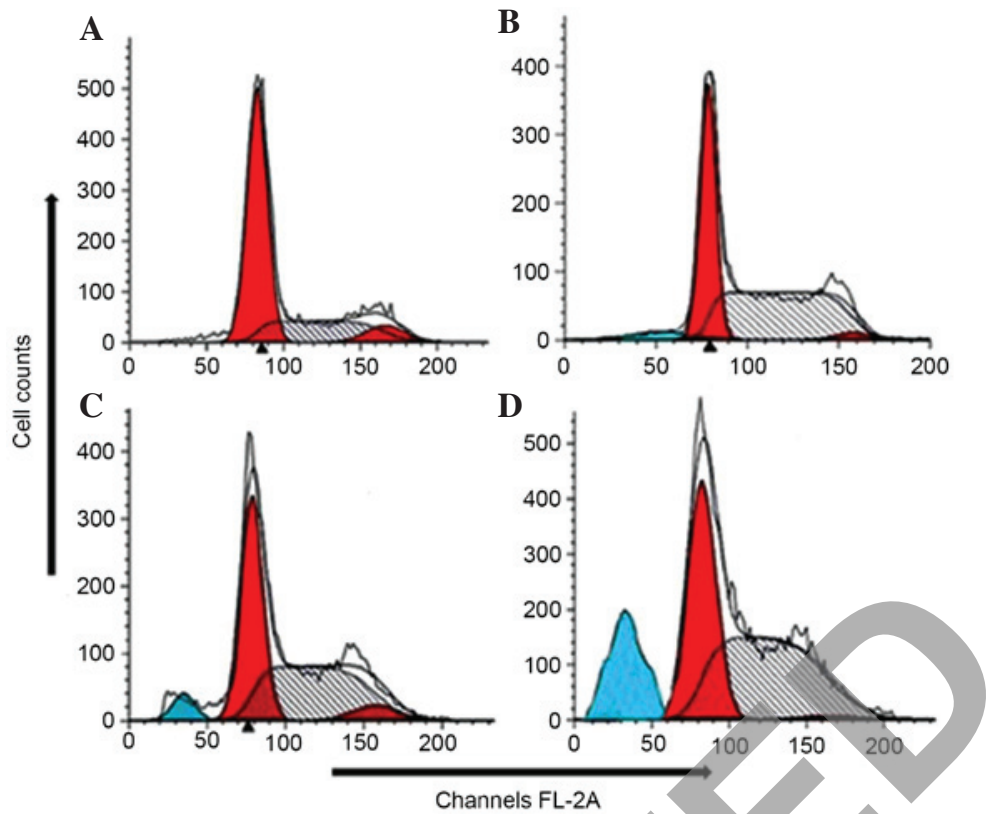

Figure 5. EEPC induced cell cycle arrest at sub-G1 phase in MG-63 human osteosarcoma cancer cells. MG-63 cells were subjected to (A) $0 \mu \mathrm{g} / \mathrm{ml}$ (control), (B) $40 \mu \mathrm{g} / \mathrm{ml}$, (C) $80 \mu \mathrm{g} / \mathrm{ml}$ and (D) $150 \mu \mathrm{g} / \mathrm{ml}$ EEPC. The cells in the sub-G1 phase (apoptotic cells) increased with an increase in EEPC dose. The DNA histogram shows the distribution and the percentage of cells in different phases of the cell cycle. EEPC, ethyl acetate extract of Potentilla chinensis.

was also examined by observation of the formation of DNA ladder. As shown in Fig. 6, the DNA ladder appeared to be more evident with the increasing extract concentration; however, no DNA fragments were observed in the control group (Fig. 6, $0 \mu \mathrm{g} / \mathrm{ml}$ ). However, 40, 80 and $150 \mu \mathrm{g} / \mathrm{ml}$ doses of the extract after $48 \mathrm{~h}$ exposure led to a substantial increase in DNA fragmentation (Fig. 6, right panel). The DNA fragmentation is a hallmark of apoptosis, further confirming that the EEPC extract induced cell death through apoptosis.

Effects of EEPC extract on the migration of MG-63 osteosarcoma cancer cells. In this experiment, the effect of EEPC extract on the migration in MG-63 osteosarcoma cells was examined. Confluent cells were scratched and then treated with EEPC extract in complete medium for $48 \mathrm{~h}$. The number of cells that migrated into the scratched area was captured (magnification, x40; inverted light microscope; Olympus America, Inc., Center Valley, PA, USA) and calculated as a percentage (\%) of migration. As shown in Figs. 7 and 8 , EEPC extract significantly reduced MG-63 cell migration in a concentration-dependent manner.

\section{Discussion}

Apoptosis or programmed cell death is a key strategy for eliminating cancerous cells. It acts as a protective mechanism that abolishes potentially harmful or damaged cells before the appearance of malignancy, without activating the inflammatory responses $(15,16)$. Several chemotherapeutic drugs including doxorubicin (17), cisplatin (18) and tamoxifen (19) cause cell cycle arrest and induce apoptosis to eradicate the cancerous cells. This process is characterized by distinct morphological changes, including membrane blebbing, cell shrinkage, loss of mitochondrial membrane potential $(\Delta \Psi \mathrm{m})$, chromatin condensation and DNA fragmentation. Two

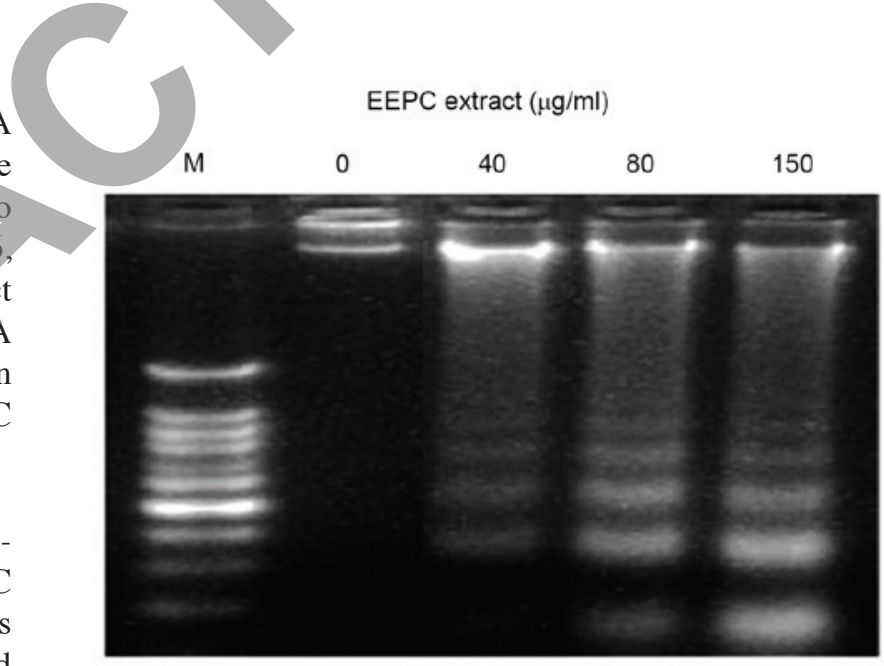

Figure 6. EEPC extract induces DNA fragmentation in MG-63 human osteosarcoma cancer cells. The cells were treated with $0,40,80$ and $150 \mu \mathrm{g} / \mathrm{ml}$ of extract for $48 \mathrm{~h}$. Cells from each sample were harvested for DNA gel electrophoresis as described. EEPC, ethyl acetate extract of Potentilla chinensis.

distinct pathways of apoptosis in living cells have been identified, the extrinsic and intrinsic pathways (20): The extrinsic pathway is arbitrated through cell surface death receptor, resulting in the activation of caspase-8. Conversely, the intrinsic pathway is reliant on numerous cell stress stimuli, leading to altered ratios of Bcl-2 family members, which affect cytochrome $c$, Smac and apoptotic protease activating factor-1 release, resulting in caspase- 9 and -3 activation. Besides apoptosis, deregulations of cell cycle checkpoints, including those of the G1/S and G2/M phases have been reported to be connected with cancer development (21). Cell cycle arrest offers a chance for DNA repair to take place, therefore inhibiting replication of the damaged template. It is regarded as one of the effective strategies for eliminating 
A

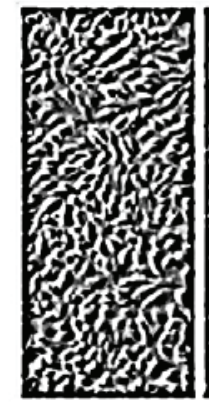

C

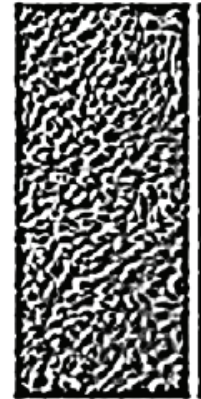

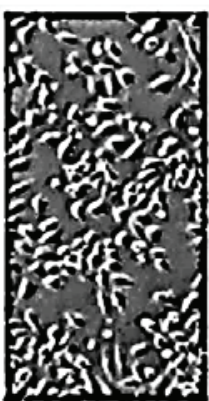
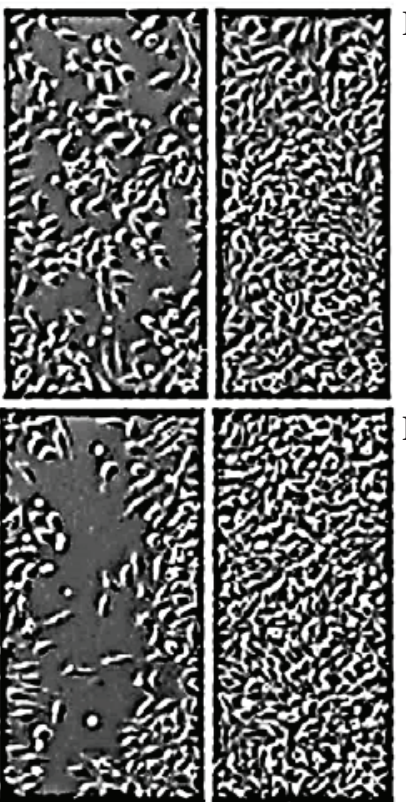
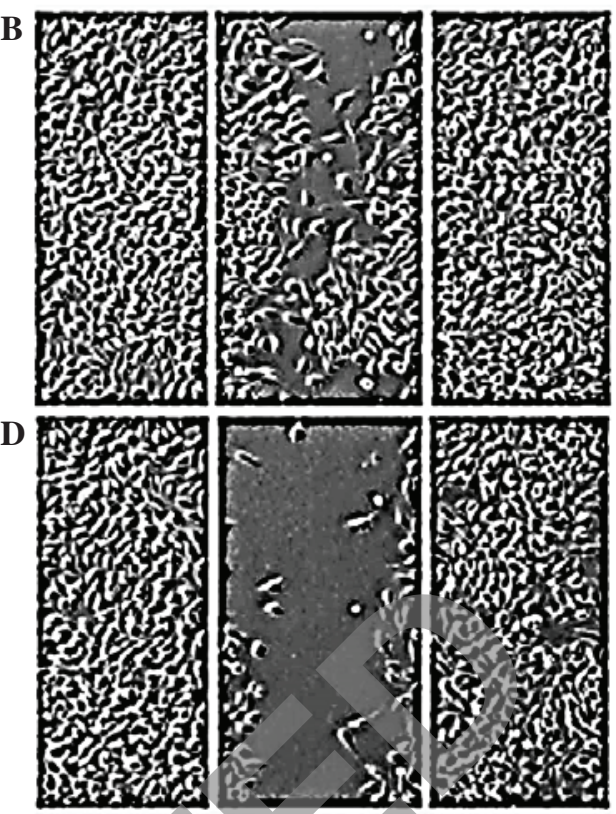

Figure 7. Effect of EEPC extract on MG-63 human osteosarcoma cancer cell migration in vitro. Images of wounds treated with (A) 0, (B) 40, (C) 80 and (D) $50 \mu \mathrm{g} / \mathrm{ml}$ EEPC extract for $48 \mathrm{~h}$. The number of cells that migrated into the scratched area was calculated as a percentage of migration.

cancer cells. Several natural plants have been investigated for their cytotoxicity in cancer targeting apoptosis (22).

The current study demonstrated the antitumor effects of the EEPC, which is a well-known Chinese medicinal plant with wide range of traditional uses. An MTT assay was used to evaluate the cell viability against human MG-63 osteosarcoma cancer cells as well as the fR-2 normal epithelial cell line in order to determine whether the extract exerts a selective cytotoxic effect. The extract exhibited potent, dose-dependent and selective cytotoxic activity against MG63 cancer cells. The results also showed that the extract displayed decreased cytotoxicity towards the normal cell line, and as such was specific only towards cancer cells. Furthermore, the effect of the extract on cell morphology and apoptosis induction was also evaluated using phase contrast microscopy and an Annexin V assay. The extract induced characteristic morphological changes in cancer cells, such as altered cell shape, shrinkage and blebbing. When the cells were treated with 40,80 and $150 \mu \mathrm{g} / \mathrm{ml}$ of the EEPC extract for $48 \mathrm{~h}$, the average proportion of Annexin V-staining positive cells (total apoptotic cells) significantly increased from $5.6 \%$ in control to $24.2,38.8$ and $55.7 \%$ respectively. The extract induced early and late apoptosis in the cancer cells. The effect of the extract on cell cycle arrest using flow cytometry was further evaluated. The results revealed that EEPC induced cell cycle arrest at the sub-G1 phase in MG-63 human osteosarcoma cancer cells. This increase in the sub-G1 population was attended by a corresponding decline of the cells in s-phase and G2/M phase of the cell cycle. As compared with the control, extract treated cells showed a significant proportion of apoptotic cells. The DNA ladder appeared to be more evident with the increasing extract concentration, however, no DNA fragments were observed in the control groups. However, 40, 80 and $150 \mu \mathrm{g} / \mathrm{ml}$ doses of the extract after $48 \mathrm{~h}$ exposure led to a substantial increase in DNA fragmentation. The DNA

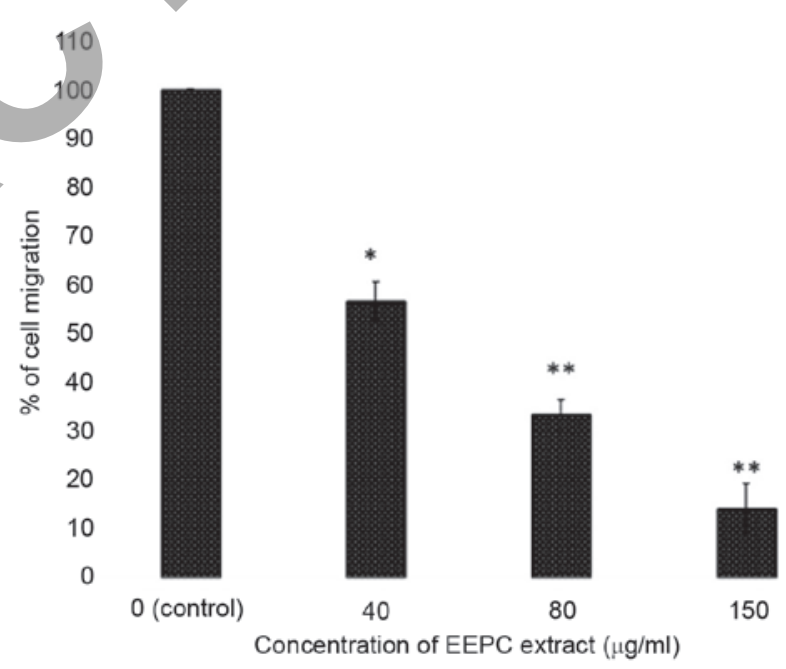

Figure 8. Graphical representation of the EEPC extract induced reduction in the migration of MG-63 osteosarcoma cancer cells. Data are shown as the mean \pm standard deviation of three independent experiments. ${ }^{*} \mathrm{P}<0.05$ and ${ }^{* *} \mathrm{P}<0.01$ vs. control. EEPC, ethyl acetate extract of Potentilla chinensis.

fragmentation is a hallmark of apoptosis, further confirming that the EEPC extract induced cell death through apoptosis.

Migration and invasion are hallmarks of malignancy. Inhibition of migration and invasion of cancer may be expected to be associated with a reduction of the malignancy grade of cancers. Therefore, the effect of the extract on cell migration in MG-63 osteosarcoma cancer cells was also assessed using an in vitro wound healing assay. It was demonstrated that EEPC extract evidently reduced MG-63 cell migration in a concentration-dependent manner.

In conclusion, the present study reported promising anticancer effects of EEPC, which were mediated through apoptosis induction, cell cycle arrest, DNA damage and inhibition of cell 
migration. Notably, the extract exhibited a selective cytotoxic effect against MG-63 osteosarcoma cells, while the normal epithelial cells were less susceptible to the different extract doses. This study also confirms the use of EEPC as an anticancer agent. Considering the potential cytotoxic effects of the EEPC extract, further studies are required to investigate its cytotoxic potential in addition to its toxicity profile using different in vivo models and further mechanisms of action, so that it may serve as a novel therapeutic agent against osteosarcoma.

\section{References}

1. Enneking WF and Springfield DS: Osteosarcoma. Orthop Clin North Am 8: 785-803, 1977.

2. Ottaviani G and Jaffe N: The epidemiology of osteosarcoma. Cancer Treat Res 152: 3-13, 2009.

3. Ferguson WS and Goorin AM: Current treatment of osteosarcoma. Cancer Invest 19: 292-315, 2001.

4. Bacci G and Lari S: Adjuvant and neoadjuvant chemotherapy in osteosarcoma. Chir Organi Mov 86: 253-268, 2001 (In English and Italian).

5. La Quaglia MP: Osteosarcoma. Specific tumor management and results. Chest Surg Clin N Am 8: 77-95, 1998

6. Newman DJ and Cragg GM: Natural products as sources of new drugs over the last 25 years. J Nat Prod 70: 461-477, 2007.

7. Chaoluan L, Ikeda H and Ohba H: Potentilla Linnaeus, Sp. Pl. 1: 495. 1753. In: Flora of China 9: 291-327, 2003. /www.efloras.org/.

8. Xue PF, Luo G, Zeng WZ, Zhao YY and Liang H: Secondary metabolites from Potentilla multifida L. (Rosaceae). Biochem Syst Ecol 33: 725-728, 2005

9. XuePF, Yin T,Liang HandZhao YY: Study on chemical constituents of Potentilla discolor. Chin Pharm J 40: 1052-1054, 2005.

10. Lu LU, Sujun LI, Zonglin LIU, Bo YU, Huan GUO and Jiguo HE: Study on hypoglycemic mechanism of Potentilla chinensi extracts to diabetic mice. Food Sci 29: 387-391, 2008.
11. Lim JP, Lee HG, Jeon H and Bora L: Anti-inflammatory effect of Potentilla chinensis herbal water extract on the proteinase activated receptor-2-mediated paw edema. Korean J Orient Physiol Pathol 23: 1444-83, 2009.

12. Liu P, Duan HQ, Pan Q, Zhang YW and Yao Z: Triterpenes from herb of Potentilla chinensis. Zhongguo Zhong Yao Za Zhi 31: 1875-1879, 2006 (In Chinese).

13. Li PL, Lin CJ, Zhang ZX and Jia ZJ: Three new triterpenoids from Potentilla multicaulis. Chem Biodivers 4: 17-24, 2007.

14. Wang QH, Li ZY, Shen Y, Lin HW, Shu W and Zhou JB Studies on triterpenoids from Potentilla chinensis. Zhongguo Zhong Yao Za Zhi 31: 1434-1436, 2006 (In Chinese).

15. Kaufmann SH and Hengartner MO: Programmed cell death: Alive and well in the new millennium. Trends Cell Biol 11: 526-534, 2001.

16. Reed JC: Apoptosis-regulating proteins as targets for drug discovery. Trends Mol Med 7: 314-319, 2001.

17. Lüpertz R, Wätjen W, Kahl R and Chovolou Y: Dose and time-dependent effects of doxorubicin on cytotoxicity, cell cycle and apoptotic cell death in human colon cancer cells. Toxicology 271: 115-121, 2010.

18. He G, Kuang J, Khokhar AR and Siddik ZH: The impact of S- and G2-checkpoint response on the fidelity of G1-arrest by cisplatin and its comparison to a non-cross-resistant platinum (IV) analog. Gynecol Oncol 122: 402-409, 2011.

19. Han P, Kang JH, Li HL, Hu SX, Lian HH, Qiu PP, Zhang J, Li WG and Chen QX. Antiproliferation and apoptosis induced by tamoxifen in human bile duct carcinoma QBC939 cells via upregulated p53 expression. Biochem Biophys Res Commun 385: 251-256, 2009.

20. Earnshaw WC, Martins LM and Kaufmann SH: Mammalian caspases: Structure, activation, substrates, and functions during apoptosis. Annu Rev Biochem 68: 383-424, 1999.

21. Sun XM, MacFarlane M, Zhuang J, Wolf BB, Green DR and Cohen GM: Distinct caspase cascades are initiated in receptor-mediated and chemical-induced apoptosis. J Biol Chem 274: 5053-5060, 1999.

22. Buolamwini JK: Cell cycle molecular targets in novel anticancer drug discovery. Curr Pharm Des 6: 379-392, 2000. 